
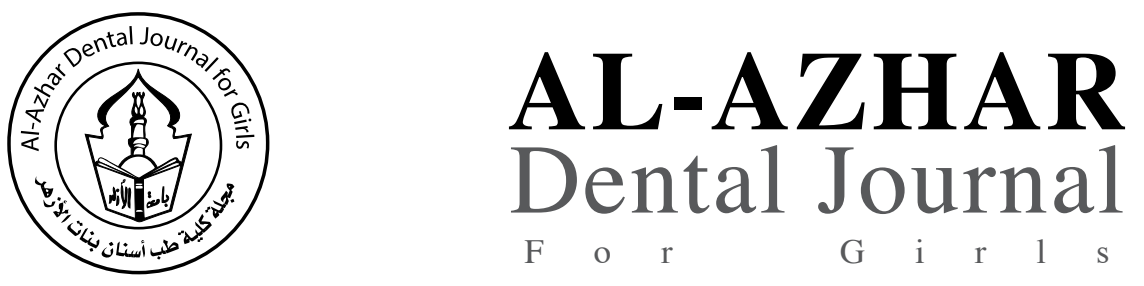

The Official Publication of The Faculty of Dental Medicine For Girls, Al-Azhar University Cairo, Egypt.

ADJ-for Grils, Vol. 3, No. 1, January (2016) - PP. 23:30

\title{
Marginal Accuracy and Fracture Strength of Implant Supported Zirconia Copings Constructed Using CAD/CAM and MAD/MAM Techniques
}

\author{
Ayat Gamal Abd El Mo'men Montaser ${ }^{(1)}$, Atef F Ahmed ${ }^{(2)}$ and Mona H Mandour ${ }^{(3)}$
}

Codex : 04/1601

dentaljournal.forgirls@yahoo.com

\section{KEYWORDS}

$C A D / C A M$

MAD/MAM marginal accuracy,

fracture strength,

zirconia

\begin{abstract}
Purpose. The purpose of this study was to evaluate the marginal accuracy and fracture strength of single implant supported zirconia copings constructed using two different techniques; CAD/CAM and MAD/ MAM process. Materials and Methods: twenty titanium dummy implants with their respective zirconia abutments representing mandibular first premolar were embedded in epoxy resin blocks. Samples were divided into two groups according to the milling technique used for constructing zirconia copings: Group (I), $(n=10)$ : Zirconia copings milled using CAD/CAM system. Group (II), ( $\mathrm{n}=10)$ : Zirconia copings milled using MAD/MAM system. All samples were subjected to a fatigue procedure composed of 20,000 cycles of cyclic loading at 89 N. Marginal accuracy was determined using digital stereomicroscope. All specimens were loaded in a universal testing machine with the compressive load $(\mathrm{N})$ applied within the long axis of the specimen to determine the fracture resisitance. Failure load was recorded for each specimen. Data were statistically analyzed. Results: CAD/CAM copings, group (I), recorded higher mean vertical marginal gap distance value $(27.05 \pm$ $5.57 \mu \mathrm{m}$ ) than MAD/MAM copings, group (II), which recorded lower vertical marginal gap distance $(20.72 \pm 4.35 \mu \mathrm{m})$. MAD/MAM samples, group (II), recorded higher mean failure load value $(703.35 \pm 44.07$ $\mathrm{N})$ in comparison to CAD/CAM samples, group (I), (416.06 \pm 25.59 $\mathrm{N})$. Conclusions: MAD/MAM samples showed superior marginal accuracy and fracture strength than CAD/CAM samples.
\end{abstract}

1. Paper extracted from these title; Marginal Accuracy and Fracture Strength of Implant Supported Zirconia Copings Constructed Using CAD/CAM and MAD/MAM Techniques.

2. Demonstrator, Crowns and Bridges Department, Faculty of Dental Medicine, Al-Azhar University (Girls' branch), Egypt.

3. Professor, Head of, Crowns and Bridges Department, Faculty of Dental Medicine, Al-Azhar University (Girls' branch), Egypt.

4. Associate Professor, Crowns and Bridges Department, Faculty of Dental Medicine, Al-Azhar University (Girls' branch), Egypt. 


\section{INTRODUCTION}

The clinical use of osseointegrated implants for single tooth replacement has been well documented. A high degree of success was achieved with implants in partly edentulous jaws. This single-tooth implant has also become a predictable treatment option ${ }^{(1)}$.

Due to continued interest in esthetic dentistry, studies of restorations with similar dental colors have continued along with those of dental materials and technology with satisfactory strength. Zirconia has been recognized as a solution for this issue, ever since; its clinical application has been widely extended ${ }^{(2)}$.

Zirconia is a polycrystalline material without a glassy matrix. Yttrium-oxide is added to zirconia in order to stabilize the tetragonal phase at room temperature, which as a result can prevent crack propagation in the ceramic (Transformation strengthening). Zirconia has uncomplicated handling properties, excellent biocompatibility, low thermal conductivity, light transmission, no black margins and excellent mechanical properties ${ }^{(3)}$. Because of the high melting point of zirconia, it is processed by a milling method. This milling technique is one of the two major systems for producing restorations, based on the methods of image scanning and milling namely, the Computer-aided design/ Computeraided manufacture (CAD/CAM) systems and the copy milling systems (Manual - aided design / Manual - aided manufacture "MAD/MAM") ${ }^{(4,5)}$.

The CAD/CAM system applies CAD onto the images acquired by scanning a die, which is cut by following the design using a milling machine. The sintering process occurs afterward and manufactures a coping with light-curing resin on a die that is then replicated by cutting and sintering the resin ${ }^{(5,6)}$. By applying the CAD/CAM system, a dental laboratory can save time in producing cores and benefit by producing consistent results, However the system requires very expensive machines.

On the other hand, the equipment required for the copy milling system costs less, but requires a significant amount of time for zirconia- block cutting because of the manual handling required, which is considered to be highly dependent on the skill of the dental technician ${ }^{(7)}$.

All ceramic restorations must ensure requirements for strength and precision of marginal fit for clinical success. The marginal fit of any dental restoration is vital to its long-term success. Imperfect restoration's margins offer ideal recesses for plaque accumulation followed by adherence of oral bacteria. This may cause gingival irritation with consequent soft tissue breakdown ${ }^{(8)}$. The gap between the restoration and the abutment can act as a trap for bacteria, and thus, possibly cause inflammatory reactions in the peri- implant soft tissue ${ }^{(9)}$.

In addition; the clinical performance and durability of all ceramic restorations is dependent on their ability to sustain applied occlusal forces without being fractured. All ceramic systems with greater strength has been introduced to overcome failures attributed to fracture and to withstand functional forces in the oral cavity ${ }^{(10)}$.

Dental ceramics are inherently susceptible to fatigue and subsequent premature failure, especially when they are in moist environments, under high forces, and repetitive stresses during the chewing cycle causing the restoration to fracture under normal loads ${ }^{(11)}$. Ceramic restorations supported by single implant were reported to accumulate damage during cyclic loading. The accumulated damage weakens the ceramic restoration and can cause subsequent clinical failures in the form of fracture of one of the restorative components ${ }^{(12)}$.

The purpose of the present study was therefore set to compare the marginal accuracy and the fracture resistance of implant supported zirconia copings constructed using CAD/CAM and MAD/ MAM milling machines. The null hypotheses assumed that there will be no difference between marginal accuracy and fracture resistance of supported zirconia copings constructed using CAD/CAM and MAD/MAM milling machines. 


\section{MATERIALS AND METHODS}

Twenty titanium dummy implants with $4.3 \mathrm{~mm}$ platform diameter, $4.7 \mathrm{~mm}$ body diameter and 13 mm length (Nobel Biocare, U.S.A.) were used in the current study. Prefabricated $\mathrm{ZrO} 2$ abutments (Esthetic Zirconia Abutment; Reactive implant direct, U.S.A.) representing mandibular first premolar with $2 \mathrm{~mm}$ collar height, 0 angulation, circumferential $1 \mathrm{~mm}$ thick chamfer finish line, $4.3 \mathrm{~mm}$ diameter and $9 \mathrm{~mm}$ length were tightened and torqued to their corresponding dummy implants at $35 \mathrm{Ncm}$ according to their manufacturer's recommendations using torque control system (Nobel Biocare AB). Thereafter, all implants with their respective zirconia abutments were embedded in an upright position inside special specimen holders filled with epoxy resin (CMB. International, Egypt) using dental surveyor. The embedding resin had a modulus of elasticity of approximately $12 \mathrm{GPa}$, which approximates that of human bone $18 \mathrm{GPa}{ }^{(13)}$.

All samples were divided into two groups $(n=10)$ according to the method of constructing the zirconia copings, Group (I), (n=10): Zircon - biostar zirconia copings (Siladent Dr. Böhme \& Schöps GmbH, Germany) milled using CAD/CAM system. Group (II), (n=10): Ice zirconia copings (Zirkonzahn,Italy) milled using MAD/MAM system.

In group (1), the Roland machine (DWX50 Roland DG Corporation. Japan.) was used to mill the zirconia disc After the abutment scanning was completed, the coping thickness was adjusted at $0.5 \mathrm{~mm}$, while width of cementing gap was adjusted at $30 \mathrm{~mm}$. The zirconia disc was cut and milled, and then the milled coping were finally sintered.

In group (2); a silicon index was used to standardize the size and shape of the copings among both groups; Four coats of die spacer material (Tru fit, Ebay, America) were applied with 5 minutes' interval between each coat, to provide $30 \mu \mathrm{m}$ thickness. All axial surfaces of the abutments were painted leaving $1 \mathrm{~mm}$ short of finish line. After the copings were made of light-curing resin, zirconia disc were cut and milled with the Zirkonzahn system (Zirkograph 025 Echo, Zirkonzahn,Italy.) using the copy milling technique. Finally, the copy-milled copings were finally sintered. After sintering process, the copings in both groups were seated on their corresponding abutments and checked for complete seating using magnifying lens ( Hao Ming Glass, straight shank, China).

Fatigue procedure: Each sample was mounted on the lower fixed compartment of Universal testing machine (Model 3345; Instron Industrial Products, Norwood, USA). A metallic rod with round tip (3.6 $\mathrm{mm}$ diameter) attached to the upper movable compartment of the machine was applied occlusally at the middle of the occlusal surface of the coping , with tin foil sheet in-between to achieve homogenous stress distribution and minimize transmission of local force peaks. The specimens were subjected to a slowly increasing compressive load $(1 \mathrm{~mm} /$ min). The samples underwent pre-loading in a cyclic manner. Each sample was subjected to 20,000 cycles. Load was cycled at first between a specified maximum $(89 \mathrm{~N})$ and minimum $(10 \mathrm{~N})$ to avoid lateral dislocation of the loading tip during the test.

Measurement of vertical marginal discrepancy: The marginal accuracy was determined by measuring the vertical gap distance between the coping margin and the chamfer finish line of the zirconia abutment using digital stereomicrscope at fixed magnification of 90X on four points of buccal, lingual, mesial and distal surfaces, measurement at each point was repeated five times.

Measurement offracture strength: Each sample was individually mounted on the lower fixed compartment of a Universal Testing Machine (Model LRX-Plus, Lloyd Instruments, Fareham, UK) with a load cell of $5 \mathrm{kN}$-then secured in place by tightening screws. The upper plate of the machine including a metal rod (5.6 $\mathrm{mm}$ diameter spherical tip) was mounted directly over the occlusal surface of core sample. A tin foil sheet was placed between the load applicator and the specimen to ensure even stress 
distribution and minimize of the transmission of local force peaks. Samples were subjected to a slowly increasing vertical load $(1 \mathrm{~mm} / \mathrm{min})$ until fracture occurred. Load was recorded in Newtons (N).

Type of fracture: All fractured samples were examined using magnification lens $(\mathrm{X}=15)$ to assess the mode of failure. Mode of failure was assigned according to the following types: Type (C): Fracture/cracking of zirconia coping. Type (A): Fracture/cracking of zirconia abutment. Type (I): Fracture of dummy implant. Type (S): Fracture/ bending of connecting screw.

\section{Statistical analysis}

Data were analyzed by SPSS 17 (Statistical Package for Scientific Studies) for Windows using unpaired Student's t test for two independent samples. $P$-value less than 0.05 were considered significant.

\section{RESULTS}

\section{I- Results of marginal accuracy (vertical marginal gap distance " $\mu \mathrm{m}$ "):}

CAD/CAM copings, group (I), recorded higher mean vertical marginal gap distance value (27.05 $\pm 5.57 \mu \mathrm{m}$ ) than MAD/MAM copings, group (II), which recorded lower vertical marginal gap distance $(20.72 \pm 4.35 \mu \mathrm{m})$. Unpaired t test revealed that the difference was highly statistically significant $(\mathrm{p}=0.0003)$. (Table 1)

Table (1) Mean vertical marginal gap distance $(\mu \mathrm{m})$, standard deviation and Statistical analysis of tested groups $(C A D / C A M \& M A D / M A M)$.

\begin{tabular}{|c|c|c|}
\hline & $($ CAD/CAM) & (MAD/MAM) \\
\hline Mean & 27.05 & 20.72 \\
\hline Standard deviation & 5.57 & 4.35 \\
\hline t value & \multicolumn{2}{|c|}{4.0056} \\
\hline P value & \multicolumn{2}{|c|}{$0.0003 *$} \\
\hline
\end{tabular}

\footnotetext{
* Significant at $p<0.05$
}

\section{II- Results of fracture strength (failure load “N”)}

MAD/MAM samples, group (II), recorded higher mean failure load value $(703.35 \pm 44.07)$ in comparison to CAD/CAM samples, group (I), (416.06 \pm 25.59). Unpaired $t$ test revealed that the difference was extremely statistically significant $(\mathrm{p}<0.0001)$. (Table 2)

Table (2) Mean failure load (N), standard deviation and Statistical analysis of tested groups (CAD/CAM \& MAD/MAM)

\begin{tabular}{|c|c|c|}
\hline & (CAD/CAM) & (MAD/MAM) \\
\hline Mean & 416.06 & 703.35 \\
\hline Standard deviation & 25.59 & 44.07 \\
\hline t value & \multicolumn{2}{|c|}{12.6057} \\
\hline P value & \multicolumn{2}{|c|}{$<0.0001^{*}$} \\
\hline
\end{tabular}

* Significant at $\mathrm{p}<0.05$

\section{Mode of failure analysis:}

On examination of fractured samples, it was noticed that all (10) samples of CAD/CAM copings, group (I) were fractured completely type (C), while in MAD/MAM copings, group (II), (6) samples demonstrated total fracture and (4) were only cracked type $(\mathrm{C})$, while all zirconia abutments type (A), titanium dummy implants type (I) and connection screws type (S) survived after fracture load test.

\section{DISCUSSION}

Rehabilitation of completely and partially edentulous patients with dental implants is a scientifically accepted and well documented treatment modality. Dental implants have shown high capability to restore esthetics and proper function of lost teeth as their long term survival and success rates have been demonstrated. Because of the tooth like color, excellent biocompatibility and mechanical properties; ambitious efforts were made to introduce zirconia for applications in implant dentistry ${ }^{(14)}$. 
The use of zirconia abutments leads to a more natural appearing implant restoration, with no metal through or darkening of the soft tissue ${ }^{(15)}$. Increased popularity of all ceramic restorations as an alternative to metal - ceramic restorations is attributed to their excellent esthetics where dental ceramics are the most natural appearing replacement material for missing tooth substance ${ }^{(14)}$. Manufacturing processes such as (CAD/CAM) and (MAD/MAM) systems can be used to produce high-strength structural materials including zirconia-based ceramics for restoration frameworks.

The aim of the present study was directed toward evaluating the marginal accuracy and fracture strength of zirconia copings manufactured by $\mathrm{CAD} / \mathrm{CAM}$ and MAD/MAM for implant supported restorations. The marginal fit of any dental restoration is vital to its long-term success. Poor marginal adaptation of restorations increases plaque retention and changes the distribution of the microflora, which can induce the onset of periodontal disease. In addition, the restoration itself can be affected by the poor margin as variation in the fitting can create stress concentrations which may reduce the strength and long-term success of the restoration ${ }^{(16)}$. There are some variations in opinions regarding the value for clinically acceptable margin adaptation. Some studies reported values between 40 and $120 \mu \mathrm{m}^{(17-19)}$. Other studies reported wider marginal discrepancy up to $180 \mu \mathrm{m}^{(20-22)}$.

In the current study the mean marginal discrepancy for all zirconia copings were reported to be 20.72- 27.05 $\mu \mathrm{m}$ in both groups. Regarding the effect of milling technique used on the recorded vertical marginal gap mean values, the MAD/MAM samples (group II) showed significant lower marginal gap mean values than the CAD/CAM samples (group I). Thus the null hypothesis was rejected. These results are in accordance with previous studies ${ }^{(23-26)}$.

This finding could be attributed to many factors including the concept of optical impression which is based on analog or digital methods used to capture the CAD/CAM impressions. The dimensions of the infrared camera head can limit the image capture and the optical quality of the optical material sprayed on the abutment compromising marginal accuracy as well. In addition, the degree of resolution of the surface digitization device can interfere with marginal accuracy too ${ }^{(27)}$. Moreover, the optical scanning system is technique sensitive compared to mechanical digitization devices. The optical properties of the object scanned may affect the accuracy of the scanned data ${ }^{(28)}$. this technique tends to round off sharp edges, such as sharp line angles and margins, whereas the touch probe scanner reproduce sharp edges accurately, which leads to better margins in the restoration.

However, the results of the current study were in disagreements with other studies ${ }^{(29-33)}$. The authors explained their results to be due to the size of the milling bur used in copy milled group, especially at its tip, which is not small enough to mill the inner surface of the preparation accurately, therefore they suggested that the copy milling procedure is unable to create supra fine details on the inner surface as the CAD-CAM system did. In addition; the use of composite mock-ups with subsequent polymerization shrinkage might have affected the accuracy of the margins ${ }^{(4,34)}$.

Strength of dental materials is one of the most important mechanical properties that determine clinical performance and survival rate of dental restorations ${ }^{(35)}$. Mechanical cycling of ceramic materials could reduce the fracture strength of zirconia implant abutments significantly ${ }^{(36)}$.

In the current study the mean fracture strength for zirconia copings were reported to be (416.0625 703.354 N) for CAD/CAM and MAD/MAD groups respectively. MAD/MAM samples (group II) recorded a statistically significant higher mean value $(703.35 \mathrm{~N})$ in comparison to CAD/CAM samples (group I) $(416.06 \mathrm{~N})$. Thus the null hypothesis was rejected. This result is in agreement with previous study ${ }^{(37)}$. These results can be attributed to the 
difference in manufacturing process of zirconia copings which affect its strength. The differences in sintering parameters of zirconia can directly affect its microstructure and properties ${ }^{(38)}$. In addition, both milling machines used in the current study are dry milling machines with higher chance of heat accumulation within the milled ceramics compared to wet milling machines. Gabriela et al (39) and Guazzato et al ${ }^{(40)}$ reported that increased temperature within milled zirconia will relieve the compressive stresses, causing a reversal of transformation and reducing the amount of monoclinic zirconia grains.

However, the results of the current study are in disagreements with another study ${ }^{(41)}$ that found that the zirconia CAD/CAM copings showed superior fracture resistance than zirconia MAD/MAM copings. The author attributed obtained results to the irregular process of manual milling which is subjected to human variations during fabrication steps. Manual milling which results in uneven thickness of the coping in some area that leads to uneven load distribution.

The current study was not free of limitations; only vertical marginal gap distance was measured and horizontal discrepancy was not examined. The present study also did not include a veneering procedure and it which might affect the final marginal accuracy. Moreover, cementation was not performed which may affect the final outcome of marginal accuracy.

\section{CONCLUSIONS}

Within the limitations of the present study, the following conclusions can be drawn:

1. The method of construction for ceramic restorations is an important factor which influences their marginal accuracy and fracture strength.

2. Restorations milled using manual milling techniques (MAD/MAM) have superior marginal accuracy compared to computerized milled restorations (CAD/CAM).
3. Restorations milled using manual milling techniques (MAD/MAM) have superior fracture strength compared to computerized milled restoration $(\mathrm{CAD} / \mathrm{CAM})$.

\section{REFERENCES}

1. Wagenberg B, Froum SJ. A retrospective study of 1,925 consecutively placed immediate implants from 1988 to 2004. Int J Oral Maxillofac Implants 2006; 21:71-80.

2. Triwatana P, Nagaviroj N, Tulapornchai C. Clinical performance and failures of zirconia-based fixed partial dentures: a review literature. J Adv Prosthodont 2012; 4:76-83.

3. Conrad HJ, Seong WJ, Pesun IJ. Current ceramic materials and systems with clinical recommendations: a systematic review. J Prosthet Dent 2007; 98(:389-404.

4. Karl M, Graef F, Wichmann M, Krafft T. Passivity of fit of CAD/CAM and copy-milled frameworks, veneered frameworks, and anatomically contoured, zirconia ceramic, implant-supported fixed prostheses. J Prosthet Dent 2012; 107: 232-8.

5. Manicone PF, Rossi Iommetti P, Raffaelli L. An overview of zirconia ceramics: basic properties and clinical applications. J Dent 2007; 35: 819-26.

6. Song TJ, Kwon TK, Yang JH, Han JS, Lee JB. Marginal fit of anterior 3-unit fixed partial zirconia restorations using different CAD/CAM systems. J Adv Prosthodont 2013; 5: 219-25.

7. Yeo IS, Yang JH, Lee JB. In vitro marginal fit of three allceramic crown systems. J Prosthet Dent 2003; 90: 459-64.

8. James RA.Periodontal considerations in implant dentistry.J Prosthet Dent 1973;30:202-9.

9. JansenVK, Conards G, Richter EJ. Microbial leakage and marginal fit of implant abutment interfacr. Int J Oral Maxillofac Implalnts 1997; 12:527-40.

10. Larsson C. Zirconium dioxide based dental restorations. Studies on clinical performance and fracture behaviour. Swed Dent J Suppl. 2011; 213:9-84.

11. Hondrum SO. A review of the strength properties of dental ceramics .J Prosthet Dent. 1992; 67: 859-62.

12. Ohyama T, Yoshinari M, Oda Y. Effects of cyclic loading on the strength of all-ceramic materials. Int J Prosthodont 1999; 12: 28-37.

13. Kiliaridis S, Kjellberg H, Wenneberg B, Engström C. The relationship between maximal bite force, bite force 
endurance, and facial morphology during growth. A crosssectional study. Acta Odontol Scand 1993;51:323-31.

14. Meyenberg K, Luthy H, Scharer P. Zirconia posts: a new all ceramic concept for non-vital abutment teeth. J Esthet Dent 1995; 7:73-80.

15. Schneider R. Implant replacement of the maxillary central incisor utilizing a modified ceramic abutment (Thommen SPI ART) and ceramic restoration.J Esthet Restor Dent 2008; 20: 21-7.

16. Lang NP, Kiel RA, Anderhalden K. Clinical and microbiological effects of subgingival restorations with overhanging or clinically perfect margins. Journal of Clinical Periodontology 1983; 10:563-78.

17. Hunter AJ and Hunter AR. Gingival margins for crowns: a review and discussion. Part II: Discrepancies and configurations. J Prosth Dent 1990; 64: 636-42.

18. Gonzalo E, Suárez MJ, Serrano B, Lozano JF. A comparison of the marginal vertical discrepancies of zirconium and metal ceramic posterior fixed dental prostheses before and after cementation. J Prosth Dent 2009; 102: 378-84.

19. Holmes JR, Sulik WD, Holland GA, Bayne SC. Marginal fit of castable ceramic crowns. J Prosth Dent 1992; 67: 594-9.

20. Cooper TM, Christensen GJ, Laswell HR, Baxter R. Effect of venting on cast gold full crowns. J Prosth Dent 1971; 26: 621-6.

21. Pera P, Gilodi S, Bassi F, Carossa S. In vitro marginal adaptation of alumina porcelain ceramic crowns. J Prosth Dent 1994; 72: 585-90.

22. Sulaiman F, Chai J, Jameson LM, Wozniak WT. A comparison of the marginal fit of In-Ceram, IPS Empress, and Procera crowns. Intern J Prosthod 1997; 10: 478-84.

23. Park JH , Kwon TK , Yang JH , Han JS , Lee JB , Kim SH. A Comparative Study on the Marginal Fit of Zirconia Cores Manufactured by CAD/CAM and Copy Milling Methods. J Dent 2012; 3:1-4.

24. Zaghloul $\mathrm{H}$ and Younis J. Marginal Fit of ImplantSupported All-Ceramic Zirconia Frameworks. J Oral Implant 2013; 5: 417 - 24.

25. Shetty M, Rajalakshmi S, Prasad DK. Comparison of Marginal Gap and Microleakage in Copy-Milled and Cad-Milled Zirconia copings bonded using light cure and chemical cure resin bonding systems.Journal of Indian Prosthodont Soc 2014;14:37-45.
26. Jeong SM, Kang M , Christoph W. Evaluation of marginal fidelity of copy-milled and CAD/CAM all ceramic crowns. J Korean Acad Prosthodont 2001; 39(3): 243-9.

27. Persson M, Andersson M, Bergman B. The accuracy of a high-precision digitizer for CAD/CAM of crowns. J Prosthet Dent 1995; 74:223-9

28. Person A, Anderson M, Oden A, Sandborgh G. A three dimensional evaluation of a laser scanner and a touch probe scanner. J Prosthet Dent 2006; 95:194-200.

29. Kang DR, Shim JS, Moon HS. Marginal fidelity of zirconia core using MAD/MAM system. J Korean Acad Prosthodont 2010; 48: 1-7.

30. Sattar JA, Hmedat, Adel FI, Al-Abdily. A comparison of Vertical Marginal Fit of three different types of all ceramic crown restorations (An in vitro study). Journal of Genetic and Environmental Resources Conservation 2015; 3(1): 84-92.

31. Martinez-Rus F, Ferreiroa A, Ozcan M, Pradies G. Marginal discrepancy of monolithic and veneered allceramic crowns on titanium and zirconia implant abutments before and after adhesive cementation: a scanning electron microscopy analysis. Int J Oral Maxillofac Implants 2013; 28(2): 480-7.

32. Subasi G, Ozturk N, Inan O, Bozogullari1 N. Evaluation of marginal fit of two all ceramic copings with two finish lines. Europ J Dent 2012; 6: 163-8.

33. Groten M,Axmann D, Probster L, Weber H. Determination of the minimum number of marginal gap measurements required for practical in-vitro testing. J Prosthet Dent 2000; 83:40-9.

34. Ribeiro IL, Campos F, Sousa RS, Alves ML, Rodrigues DM, Souza RO . Marginal and internal discrepancies of zirconia copings: Effects of milling system and finish line design. Indian J Dent Res 2015; 26: 15-20.

35. Zeng K, Oden A, Rowcliffe D. Evaluation of mechanical properties of dental ceramic core materials in combination with porcelains. Int J Prosthodont 1998; 11(2): 183-9.

36. Gehrke P, Dhom G, Brunner J, Wolf D, Degidi M, Piattelli A. Zirconium implant abutments: Fracture strength and influence of cyclic loading on retaining-screw loosening. Quintessence Int 2006; 37: 19-26.

37. Won Kang H, Kim H, Kim J, Myung WK. Fracture Strength of All-Ceramic 3-Unit Fixed Partial Dentures Manufactured by CAD/CAM and Copy-Milling Systems. Journal of Korean Acedemy of Dental Technology 2012; 34: 95-103. 
38. Tekeli S and Erdogan MA. Quantitative assessment of cavities in $3 \mathrm{~mol} \%$ yttria-stabilized tetragonal zirconia specimens containing various grain size. Ceram Int 2002; 28:785-9.

39. Gabriela FR , Gabriel KR, Marina A, Luiz FV, Marco AB. Effect of grinding and heat treatment on the mechanical behavior of zirconia ceramic. Braz oral res 2016; 30 (1): 1-8.
40. Guazzato M, Quach L, Albakry M, Swain MV. Influence of surface and heat treatments on the flexural strength of Y-TZP dental ceramic. J Dent 2005; 33: 9-18.

41. Sadek H.S. Adaptation and fracture resistance assessment of $\mathrm{CAD} / \mathrm{CAM}$ vs. manually milled zirconia copings. M.D.Sc. thesis. Cairo University 2010. 